\title{
Managing breast cancer in younger women: challenges and solutions
}

This article was published in the following Dove Press journal:

Breast Cancer: Targets and Therapy

21 December 2015

Number of times this article has been viewed

\author{
Foluso O Ademuyiwa' \\ Amy Cyr ${ }^{2}$ \\ Jennifer Ivanovich ${ }^{2}$ \\ Maria A Thomas ${ }^{3}$ \\ 'Department of Medicine, \\ ${ }^{2}$ Department of Surgery, \\ ${ }^{3}$ Department of Radiation \\ Oncology, Washington University in \\ St Louis School of Medicine, \\ St Louis, MO, USA
}

\begin{abstract}
Breast cancer in young women is relatively rare compared to breast cancer occurring in older women. Younger women diagnosed with breast cancer also tend to have a more aggressive biology and consequently a poorer prognosis than older women. In addition, they face unique challenges such as diminished fertility from premature ovarian failure, extended survivorship periods and its attendant problems, and the psychosocial impact of diagnosis, while still raising families. It is therefore imperative to recognize the unique issues that younger women face, and plan management in a multidisciplinary fashion to optimize clinical outcomes. This paper discusses the challenges of breast cancer management for young women, as well as specific issues to consider in diagnosis, treatment, and follow-up of such patients.
\end{abstract}

Keywords: breast cancer, young women, diagnosis, treatment

\section{Introduction}

Early-onset breast cancer is relatively rare; however, it represents the commonest cause of cancer in women under age the of $40 .{ }^{1}$ In the US, approximately 33,000 women under the age of 45 years are diagnosed with breast cancer every year, and it is the leading cause of cancer-related deaths in this age group. ${ }^{2}$ Compared to older women with breast cancer, younger women tend to have a more aggressive biology and a poorer prognosis (Table 1). Younger women with breast cancer also face unique challenges such as premature ovarian failure, psychosocial issues with ongoing careers, and raising young families, as well as extended survivorship periods and its attendant complications as summarized in Figure 1. It is therefore imperative to recognize the unique issues that younger women face and plan management in a multidisciplinary fashion to optimize clinical outcomes.

\section{Breast cancer screening}

Screening for breast cancer should begin at age 40 for average-risk women. ${ }^{3}$ This includes annual mammography and clinical breast examination (CBE). Breast selfexamination (BSE) is an additional option. For average-risk women under age 40, screening consists of CBE every 3 years with optional BSE; routine use of imaging is not recommended. Although no studies have documented improved breast cancerrelated outcomes with BSE, given that routine imaging is not warranted, most malignancies in women under 40 will be detected by patients. ${ }^{4}$ Even for young women who do undergo annual mammography, cancers that develop are more likely to present as interval cancers. ${ }^{5-7}$ For this reason as well, CBE and BSE remain important screening modalities for young women. Increased breast density seen in younger women lowers
Correspondence: Foluso O Ademuyiwa Division of Oncology, Department of Medicine, Washington University in St Louis School of Medicine,

St Louis, MO 63II0, USA

$\mathrm{Tel}+\mathrm{I} 3 \mid 4362720$ I

Fax +I 314362 7086

Email fademuyi@dom.wustl.edu 
Table I Breast cancer features in younger patients

\begin{tabular}{ll}
\hline Incidence & $\begin{array}{l}\text { More common in older women. } 4.5 \% \text { incidence } \\
\text { in women age }<40^{138} \\
\text { Presentation }\end{array}$ \\
More advanced in younger women, more \\
diagnostic delays 10,11 \\
High frequency of HR-negative disease ${ }^{29}$ \\
Genetics & As younger women are more likely to have \\
& inherited susceptibility, genetic testing is \\
& recommended for all patients $\leq 40$ years \\
Prognosis & Inferior outcome in younger patients $45,57,58$ \\
Unique considerations & $\begin{array}{l}\text { Premature ovarian failure, reduced fertility, } \\
\text { increased social stressors from raising young } \\
\text { children and active workforce participation, } \\
\text { prolonged survivorship period, bone loss }\end{array}$ \\
\hline
\end{tabular}

Abbreviation: HR, hormone receptor.

the sensitivity of mammography. ${ }^{8}$ Despite this, mammography is still an important screening tool. The incorporation of tomosynthesis, or three-dimensional mammography, will likely improve the sensitivity and specificity of mammography in women with dense breast tissue. ${ }^{9}$

\section{Diagnostic evaluation of young women with breast complaints}

Women, regardless of age, who present with symptoms, require diagnostic evaluation and a CBE. Because younger women do not undergo routine screening mammography, most will present with symptomatic and higher stage breast cancer ${ }^{10,11}$ versus women diagnosed with a screening study. Young age and symptomatic presentation are both associated with delay in diagnosis and worse outcomes. ${ }^{10-12}$ The imaging modality selected for the diagnostic workup depends on the patient's age and presenting symptoms. ${ }^{13-16}$ Masses should be evaluated by ultrasound with or without mammography, depending on the patient's age, the clinical suspicion, and the nature of the mass. Pathologic nipple discharge concerning for ductal carcinoma in situ may mandate mammography even in younger women to evaluate for calcifications. Magnetic resonance (MR) is typically not indicated for evaluation of mammographic or ultrasound abnormalities; suspicious findings on conventional imaging or examination require standard evaluation, including biopsy, even in the setting of a negative MR. Negative imaging of any type does not negate the possibility of malignancy, and therefore even in the setting of normal imaging, suspicious palpable findings require biopsy for definitive diagnosis.

\section{Genetic predisposition}

First-degree relatives of women with breast cancer have nearly a twofold increased breast cancer risk compared to the general population, and this risk is much higher when the relative is diagnosed at a young age. ${ }^{17,18}$ Large twin studies have demonstrated nearly one-third of all breast cancer is attributed to hereditary factors. ${ }^{19,20}$ However, the susceptibility genes

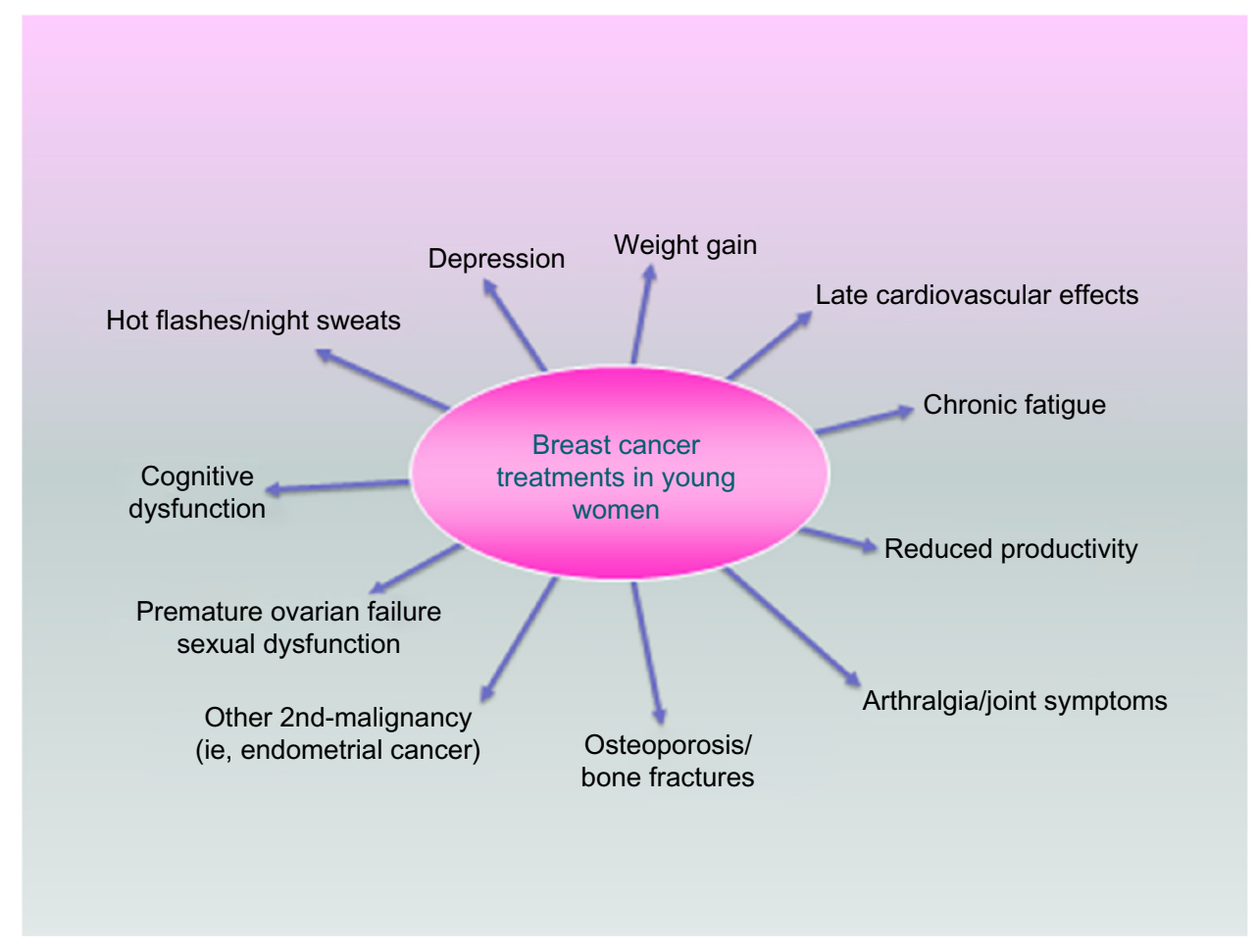

Figure I Breast cancer diagnosis and treatment effects on young women. 
identified to date account for only $20 \%-30 \%$ of the excess familial risk. ${ }^{21,22}$ Consequently, the genetic etiology for the majority of families with an increased familial breast cancer risk remains unknown.

Young age at diagnosis is a feature of hereditary disease, and it is currently recommended that all women diagnosed with breast cancer less than 40 years of age be referred for genetics assessment. A higher proportion of young women with breast cancer have germline mutations, compared to their older counterparts, with most studies evaluating the prevalence of BRCA1, BRCA2, and TP53 mutations. ${ }^{23-25}$ Furthermore, a greater proportion of young women, especially black women, have triple-negative disease, and among these women there is also an increased frequency of germline mutations, notably in $B R C A 1, B R C A 2$, and PALB2 genes. ${ }^{26}$ Identification of germline mutations has the potential to impact a woman's medical care, and to be informative for at-risk family members.

Multiple gene panels, with concurrent analysis of genes with varied levels of breast cancer risk, are now commonly used in clinical practice. Maxwell et $\mathrm{al}^{27}$ evaluated the use of a 22-gene panel among a cohort of young women with breast cancer, classifying the results into clinically actionable and unclear actionability, based on the available data of the risks associated with each gene. Only $2.5 \%$ of this cohort of 278 patients was identified with clinically actionable gene variants compared to $8.6 \%$ of patients with variants for which clinical data are deficient. ${ }^{27}$ The current lack of clinical validity for many genes makes translating clinical genetic testing results into improved patient care difficult, with the potential for overtreatment. Some investigators have advocated that genetic testing for breast cancer risk should only be offered after the clinical validity is established for the genes to be analyzed. ${ }^{28}$ Until additional cancer susceptibility genes are discovered and clinical validation of recently discovered genes is performed, clinicians will need to continue to rely on the family cancer history to help guide medical care for the majority of young women diagnosed with breast cancer.

\section{Biology of early-onset breast cancer}

Differences in pathologic characteristics between younger and older women with breast cancers have been observed in multiple studies. The Prospective study of Outcomes in Sporadic and Hereditary breast cancer is the largest to investigate factors affecting breast cancer prognosis in patients $\leq 40$ years; however, there is no comparison to older women due to the observational nature of the study. ${ }^{29}$ Although only $30 \%$ of the patients had screen-detected cancers, $50 \%$ of the patients in this multicenter study presented with nodal involvement. One-third of them were hormone receptor (HR) negative, $20 \%$ had triple-negative breast cancer, and almost $60 \%$ had poorly differentiated tumors. In addition, although majority of patients received chemotherapy in addition to endocrine therapy, $10 \%$ of those with HR-positive breast cancer developed a late relapse between years 5 and 8 . At a median follow-up of 5 years, the overall survival was $82 \%$, with the majority of deaths due to breast cancer. Another large study using the California Cancer Registry also found that $20 \%$ of adolescents and young adults with breast cancer had triplenegative disease and $54 \%$ had high-grade tumors. ${ }^{30}$ Numerous other studies have also suggested more biologically aggressive cancers in younger women. . $^{10,31-37}$

Gene expression profiling has subdivided triple-negativebreast cancer (TNBC) patients into clinically relevant subtypes now being used to design clinical trials. ${ }^{38}$ A comprehensive study on TNBC samples revealed several biomarkers, including TP53, PIK3CA, AKT1, PTEN, and HER2 mutations that may be therapeutically relevant in the future. ${ }^{39}$ Clinical trials investigating agents targeted at such aberrations are underway. For example, a recent openlabel Phase II trial investigating enzalutamide, an androgen receptor (AR) antagonist, in AR-positive advanced TNBC patients, reported a 16 -week clinical benefit rate of $35 \% .{ }^{40}$ TNBC cases that were strongly AR-positive exhibited lower proliferation rates than those that were not AR-positive. ${ }^{39}$ These AR-positive tumors tend to be rich in genes regulated by the hormonal pathway.

TNBC is an immunogenic form of breast cancer due to the frequency of mutations causing neoantigens, and the association between high rates of tumor infiltrating lymphocytes and improved response to chemotherapy and survival seen in that subset of breast cancer. ${ }^{41,42}$ Novel immune checkpoint inhibitors, such as the PDL1 and PD1 inhibitors, appear to have activity in TNBC patients as well. Two studies utilizing these agents in the advanced TNBC setting reported durable clinical benefits in patients with PDL1-positive TNBC. ${ }^{43,44}$ Thus, new predictive markers in TNBC may prove to be therapeutically relevant in the future.

Several groups have also found gene expression profile differences between breast cancers occurring in younger versus older women. In the largest study evaluating age-related biological differences in breast cancer, Azim et $\mathrm{al}^{45}$ found that genes enriched in processes related to immature mammary cell populations (RANKL, c-kit, BRCA1, mammary stem cells, and luminal progenitors cells) and growth factor signaling $(M A P K, P I 3 K)$ were predominant in younger women. 
Analysis of clinically annotated microarray data from 784 breast cancer patients also revealed that young women $\leq 45$ years had lower mRNA expression of $E R \alpha$, $E R \beta$, and PR, but higher expression of HER 2 and $E G F R$ as opposed to women $\geq 65$ years. ${ }^{46}$ In women $<40$ years, gene expression profiling further showed lower expression of $E R \alpha$ and $E R \beta$ compared with women $40-50$ years. In addition, gene sets unique to younger women included those related to biologically relevant and potentially actionable processes such as immune function, mTOR/rapamycin pathway, hypoxia, $B R C A 1$, stem cells, apoptosis, histone deacetylase, and multiple oncogenic signaling pathways.

Differences in biology in young women also differ by race. In a large Surveillance, Epidemiology, and End Result (SEER) study involving over 126,000 women aged $\leq 49$ years with breast cancer, we have previously reported that a higher proportion of blacks versus whites developed breast cancer under age 40. A higher proportion of blacks also presented with HR negative, more advanced stage, and higher grade tumors. ${ }^{47}$ In the Carolina Breast Cancer Study, the prevalence of basal-like breast cancer was highest (39\%) among black premenopausal women compared with other groups of patients $(14 \%-16 \%){ }^{48}$ This has also been observed in other studies in the US. ${ }^{49,50}$

\section{Prognosis}

A recent study showed an increase in the incidence of young women aged 25-39 years diagnosed with metastatic breast cancer from 1.53 to 2.90 per 100,000 from 1976 to $2009 .{ }^{51}$ Several reasons such as stage migration, improved surveillance, and population-based changes in breast cancer risk factors may be implicated. This increase is particularly concerning as young age is an independent adverse factor for poor prognosis among women with breast cancer., ${ }^{1,52-56}$ The clinical outcome is worsened for very young women under age 35 , with the hazard of death increasing by every 1 year decrease in age.$^{57}$ It is also apparent that the effect of age on outcome is modified by breast cancer subtype. A study by Sheridan et a ${ }^{58}$ showed that within the HR-positive subtype, younger age carried a worse prognosis than older age. This has also been confirmed in Azim et al's ${ }^{45}$ study, where they found an inferior relapse-free survival with young age in the HRpositive/HER2-negative subtype in a subgroup analysis.

\section{Treatment}

\section{Locoregional treatment - surgery}

Young women with breast cancer have similar surgical options as older women. These include breast conserva- tion therapy (BCT) (partial mastectomy with radiation) or mastectomy. Although young age at diagnosis is associated with a higher risk of local recurrence and more aggressive phenotypes, data suggest no survival gains with mastectomy compared to BCT, and there does not appear to be a survival advantage with contralateral prophylactic mastectomy either. ${ }^{59-63}$ Therefore, young age alone is not a contraindication to BCT. Despite this, bilateral mastectomies are on the rise in women of all ages. ${ }^{61-63}$ This is likely due to patient and physician perception of improved outcomes and due to improved reconstruction techniques and cosmesis. Immediate and immediate-delayed reconstruction are now preferred, and many women are candidates for nipple sparing procedures with immediate or immediate-delayed reconstruction. Nipple sparing procedures are increasingly being offered as data supports the oncologic safety, and these procedures are associated with better self-image. ${ }^{64,65}$

\section{Locoregional treatment - radiotherapy}

After partial mastectomy, adjuvant whole breast radiation has been shown to reduce the risk of ipsilateral breast tumor recurrence, as well as improve breast cancer survival. ${ }^{66,67}$ Adjuvant radiation is especially important for young women in this setting, as their absolute risk of local recurrence is higher than for older women, and as a result, younger women have a greater absolute benefit from adjuvant radiation. ${ }^{67}$

For young women with early-stage breast cancer, there are important considerations with regards to treatment volume. Accelerated partial breast irradiation (APBI) may not be an appropriate option for young women. Although results from the NSABP B-39 trial, ${ }^{68}$ comparing whole and partial breast radiation, are pending, there are several published consensus statements describing APBI selection criteria. All include a minimum patient age in their criteria, ranging from 45 to 60 years as the suggested minimum age. ${ }^{69-71}$ This is based on the existing published literature on APBI which primarily includes women over 50, the concern for increased risk of multifocal and multicentric disease in younger women, and the known higher local recurrence rates seen in young women who receive whole breast radiation. NSABP B-39 trial included women over 18 years old, and we await the results from this trial.

Other considerations with regards to dose and fractionation include the use of boost and hypofractionation. In the European Organization for Research and Treatment of Cancer trial, use of boost reduced the 20-year cumulative incidence of ipsilateral breast tumor recurrence from $16.4 \%$ to $12.0 \%$ (hazard ratio: $0.65, P<0.0001) .^{72}$ The benefit of a boost 
was found to be greatest for young women. The absolute risk reduction was $4.4 \%$ in the entire cohort, and $11.6 \%$ for women under 40. Hypofractionated whole-breast schedules have been found to be as effective as standard fractionation for certain populations. However, majority of these data were obtained in women over 50 years old, and therefore the American Society for Radiation Oncology guidelines on fractionation support the use of hypofractionation only for women over 50 , who also meet the other specified criteria. ${ }^{73}$ Until further evidence is available for younger women, the standard of care for these women includes delivery of wholebreast radiation with standard fractionation.

For women with locally advanced breast cancer, randomized trials have demonstrated a locoregional recurrence and survival benefit to postmastectomy radiation for women with large primary tumors $>5 \mathrm{~cm}$, invasion of the skin or chest wall, or lymph node involvement. ${ }^{74-76}$ Retrospective analysis of 107 stage II or III patients aged $\leq 35$ years treated with or without adjuvant radiation following mastectomy showed that patients who received postmastectomy radiation compared with those who did not had a better 5-year local control and overall survival rates. ${ }^{77}$ Since young age and/or premenopausal status are risk factors for locoregional recurrence after mastectomy, some young women with node negative disease may benefit from postmastectomy radiation if they have additional risk factors. ${ }^{78-80}$

For most breast cancer scenarios, young women have a higher risk of local and regional recurrence, and therefore derive an even greater absolute benefit from adjuvant radiation than older women. Given their young age and potential for long-term survival, special care must be taken during radiation treatment planning to minimize radiation exposure to adjacent organs in order to reduce the risk of late effects and secondary malignancies.

\section{Systemic treatment - endocrine}

The Early Breast Cancer Trialists' Collaborative Group's (EBCTCG) meta-analyses demonstrated that 5 years of adjuvant tamoxifen improved the annual breast cancer death rate by one-third and recurrence risk by $50 \%$ for all women with HR-positive cancers irrespective of age. ${ }^{81}$ However, approximately $10 \%$ of those with HR-positive cancers will develop a late relapse beyond year 5; therefore, there has been interest in extending adjuvant endocrine therapy to prevent later relapses. In the Adjuvant Tamoxifen: Longer Against Shorter trial, women with early stage breast cancer were randomly assigned to continue tamoxifen to 10 years or stop at $5 .^{82}$ Allocation to 10 years was associated with reductions in the risk of recurrence, improvements in breast cancer specific survival, and overall survival. Similarly, in the UK adjuvant Tamoxifen-To offer more? trial, 10 years of adjuvant tamoxifen reduced late breast cancer recurrences and mortality among women with HR-positive cancers. ${ }^{83}$ The group that continued tamoxifen to year 10 had further reductions in recurrence, from year 7 onward, as well as breast cancer mortality after year 10 . Based on these and other studies, the American Society for Clinical Oncology clinical practice guideline now recommends treatment with adjuvant tamoxifen for 10 years in women with stage I-III HR-positive cancers. While these results were not restricted to young women, in clinical practice, young patients who are believed to have a worse prognosis are generally being considered for 10 rather than 5 years of tamoxifen.

An alternative form of endocrine manipulation involves ovarian suppression (OS). Although, the prognosis for premenopausal women who have chemotherapy-induced amenorrhea (CIA) is better than for those who do not have CIA, the prognostic value of therapeutic OS remains unclear. ${ }^{84-86}$ The Suppression of Ovarian Function (SOFT) trial was designed to determine the utility of dual endocrine blockade by adding OS to tamoxifen and also to determine the benefit of an aromatase inhibitor with OS for premenopausal patients. ${ }^{87}$ Premenopausal women were assigned to either 5 years of tamoxifen, tamoxifen plus OS, or exemestane plus OS. At 5 years, $90.9 \%$ of those who received exemestane with OS were free from breast cancer, versus $88.4 \%$ in the tamoxifen plus OS arm, versus $86.4 \%$ in the tamoxifen alone group. In the subgroup of women younger than 35 years, the rate of freedom from breast cancer at 5 years was $83.4 \%$ for those assigned to exemestane plus OS, 78.9\% for those assigned to tamoxifen plus OS, and $67.7 \%$ for patients assigned to tamoxifen alone. Similarly, the Tamoxifen and Exemestane Trial (TEXT) was designed to compare exemestane plus OS versus tamoxifen plus OS also in premenopausal women. ${ }^{88}$ In the combined analysis of both SOFT and TEXT trials, the 5-year rate of freedom from breast cancer was $92.8 \%$ in those receiving exemestane plus OS, versus $88.8 \%$ for those assigned to receive tamoxifen plus OS. The symptom burden of OS with either tamoxifen or exemestane is higher than tamoxifen alone and different depending on what drug is given in combination with OS. Patients who receive tamoxifen have more vasomotor symptoms, while those who receive exemestane have more arthralgia, sexual dysfunction, and vaginal dryness. ${ }^{89}$ These side effects need to be discussed with individual patients prior to electing treatment. Results from these studies show that even in premenopausal women 
with early stage breast cancer, the outcomes in those with HRpositive cancers is very good in general; however, there is still a need to define who merits more aggressive therapy. In addition, further tools and research are needed on compliance, management of menopausal symptoms, bone loss, cognitive problems, and sexual dysfunction, and careful monitoring of late side effects such as secondary malignancies.

\section{Systemic treatment - chemotherapy}

The preferred chemotherapy regimens remain the same for all patients with early stage breast cancer irrespective of age. In general, for most high-risk breast cancer patients, combination regimens including anthracyclines and taxanes are employed. The EBCTCG meta-analyses, evaluated the benefits of adjuvant polychemotherapy on outcomes in younger versus older women. ${ }^{81}$ Anthracycline-based chemotherapy combinations had a larger impact in reducing the annual breast cancer death rate for women younger than 50 years (38\% reduction) versus 20\% for those aged 50-69 years. In addition, there was also a threefold age-related benefit for polychemotherapy versus no chemotherapy for women $<50$ years versus women 50-69 years with larger benefits for recurrences than mortality. The 5-year improvements from chemotherapy were approximately twofold for HR-negative versus HR-positive cancers, but the 15-year improvements were less dependent on HR status, likely due to differences in timing of recurrences with HR-negative versus HR-positive cancers. Preferred National Comprehensive Cancer Network (NCCN) guidelines for adjuvant chemotherapy for high-risk HR-breast cancer patients include several regimens such as doxorubicin plus cyclophosphamide followed by paclitaxel or docetaxel plus cyclophosphamide.

\section{Systemic treatment - biologic therapy}

Patients who have HER2+ breast cancer receive trastuzumab as part of their (neo)adjuvant systemic treatment based on improvements in overall survival seen in large randomized trials. ${ }^{90-93}$ Young patients also derive similar benefits from adjuvant trastuzumab as older patients. ${ }^{12}$ Pertuzumab is a humanized monoclonal antibody directed at HER2 and is approved in combination with trastuzumab and chemotherapy for treatment of HER2+ breast cancers in the neoadjuvant and advanced settings based on several studies. ${ }^{94-96}$

\section{Unique considerations Fertility preservation}

Among the unique concerns for young women with breast cancer are treatment-induced ovarian failure and infertility.
The risk of infertility varies according to age, reproductive reserve, chemotherapy agent, duration of treatment, and dose administered ${ }^{97}$ Alkylating agents are among those with the highest gonadotoxic properties. ${ }^{98}$ The true rates of infertility after breast cancer treatments have been difficult to ascertain as there is no consensus on what constitutes infertility. Different surrogates used in different studies include amenorrhea, estradiol, anti-Mullerian hormone, inhibin B, and follicle count. ${ }^{99,100}$

Young women who are desirous of future childbearing should be properly counseled by an oncofertility specialist on options for fertility preservation prior to chemotherapy. Existing reproductive options include embryo and oocyte cryopreservation, cryopreservation of ovarian tissue, or OS with luteinizing hormone releasing hormone (LHRH) agonists. ${ }^{101-103}$ The POEMS study randomized 257 premenopausal women with HR-negative breast cancer to receive standard chemotherapy with or without goserelin to determine if goserelin reduced ovarian failure. ${ }^{104}$ The ovarian failure rate was $8 \%$ in the intervention group versus $22 \%$ in the chemotherapy group. In addition, 22 patients in the goserelin group achieved at least 1 pregnancy versus 12 in the standard group, although more women in the goserelin group attempted pregnancy. While these data are encouraging, the use in those with HR-positive cancer is cautioned, as this study only included those with HR-negative cancer. Although less of an issue with LHRH agonists that are administered during chemotherapy, practical barriers limiting fertility preservation are cost, insurance, absence of a male partner, and chemotherapy timing issues.

Retrospective studies have suggested no worsening of breast cancer outcomes in patients who become pregnant. ${ }^{105-108}$ POSITIVE (Pregnancy Outcome and Safety of Interrupting Therapy for women with endocrine responsIVE Breast Cancer) is an ongoing trial, designed to evaluate the safety and outcomes of women with HR-positive cancers who interrupt endocrine therapy for childbearing. This trial seeks to enroll women under age 42 who have received 18-30 months of endocrine therapy and who then stop endocrine therapy temporarily to attempt pregnancy. ${ }^{109}$ Guidelines also recommend avoiding pregnancy within 6 months of systemic therapy completion, due to teratogenicity. ${ }^{110,111}$

\section{Pregnancy-associated breast cancer}

The incidence of pregnancy at the time of breast cancer diagnosis is approximately $1.5 \%$, and breast cancer is the most common pregnancy-associated malignancy in women. ${ }^{12-114}$ A confirmed diagnosis of malignancy should prompt 
diagnostic mammography in addition to ultrasound with uterine shielding. ${ }^{115}$ Fine needle aspiration may be difficult to interpret in the setting of pregnancy-related proliferative changes; ${ }^{116}$ core biopsy is preferred. The pathologist should be alerted to the patient's gravid state. Staging should be directed by signs and symptoms and by clinical stage as for the nonpregnant patient. Computed tomography, plain X-ray, and nuclear medicine studies expose the fetus to radiation, and so risks and benefits of this exposure need to be weighed. Nuclear medicine studies are typically avoided due to a lack of safety data, and breast MR, which requires gadolinium contrast, is not safe during pregnancy. ${ }^{117,118}$

Surgery is often the safest mode of treatment during early pregnancy as endocrine and cytotoxic therapies are contraindicated during the first trimester. ${ }^{119}$ For patients who undergo surgery early in pregnancy and who do not need adjuvant chemotherapy, radiation may be delayed many months although studies suggest worse outcomes with such delays. ${ }^{120}$ Fetal radiation exposure is associated with birth defects, mental retardation, childhood malignancy, and other complications, and as the fetus grows its proximity to the breast increases, the potential for fetal radiation exposure increases. ${ }^{119,121}$ Therefore, radiation is contraindicated in the third trimester. Clinically node-negative women undergo axillary staging with a sentinel lymph node biopsy. Traditionally, radioisotope was avoided due to the risk of radiation exposure to the fetus. More recent data suggest that the dose to the fetus is small, and available data suggest no negative impact on pregnancy outcomes with the use of radioisotope. ${ }^{122,123}$ This method of sentinel node mapping may be preferred due to continued concerns about teratogenicity or maternal anaphylaxis with methylene blue and isosulfan blue dye, respectively, both of which are Pregnancy Class C drugs. A small series, however, has not demonstrated negative pregnancy outcomes with the use of blue dyes. ${ }^{123}$ The potential risks and benefits of the sentinel node procedure need to be discussed with patients preoperatively.

Fetal malformations are seen with first trimester exposure to chemotherapy. ${ }^{124}$ Anthracycline-based regimens have the most available data and can be given during the second and third trimesters. ${ }^{125-127}$ Chemotherapy should be withheld ideally at least 3 weeks before confinement to avoid cytopenias at the time of delivery. Other systemic therapies such as endocrine therapy and trastuzumab are contraindicated during pregnancy. ${ }^{128}$

\section{Bone health}

Young women with breast cancer are at higher risk of longterm side effects from cancer treatments and survivorship due to the longer life expectancy. One particular area which has received a lot of recent attention is bone health. Although fragility fractures are more common in women over 50 years, several factors lead to bone compromise in younger women treated for breast cancer. Androgens and estrogens are regulators of bone growth, and consequently, estrogen deficiency is a key determinant in bone loss. Cancer treatments with chemotherapy can lead to estrogen deficiency via gonadal dysfunction, and also impair bone health via direct effects on bone metabolism or systemic steroids commonly used as supportive medications during chemotherapy. Radiation can impair bone integrity in the treated radiation field. Hormonal treatment designed to induce hypogonadism also leads to accelerated bone loss. In premenopausal women receiving endocrine therapy for breast cancer, changes in bone mineral density have been observed with tamoxifen, ovarian suppression, tamoxifen or aromatase inhibitors with ovarian suppression, and oophorectomy. ${ }^{129-131}$ Thresholds for pharmacologic intervention with bisphosphonates or RANK ligand inhibitors include a history of osteoporosis, fragility fractures, and osteopenia with additional risk factors. Several studies have confirmed that antiresorptive therapies maintain or increase bone mineral density in women or men treated with endocrine therapy. ${ }^{129,132-137}$ While this is encouraging, it remains unclear what impact these treatments have on the incidence of fractures in those at risk.

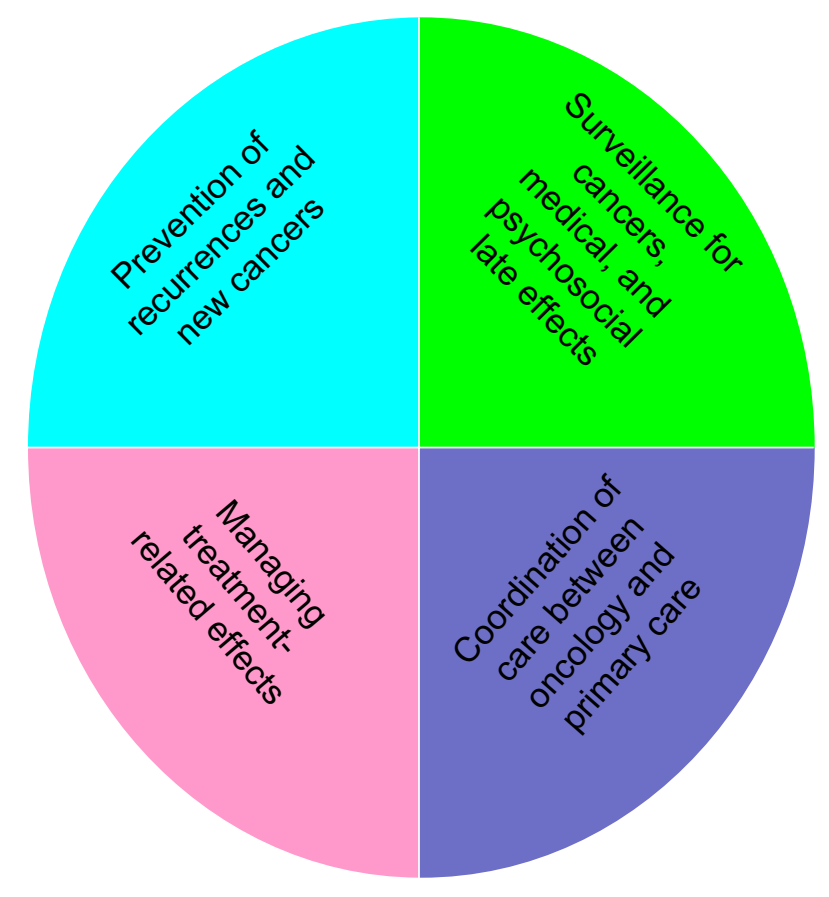

Figure 2 Essential components of a survivorship plan. 


\section{Conclusion}

Young patients with breast cancer face unique management challenges that are best addressed in a multidisciplinary setting. Currently, treatment recommendations are made on tumor characteristics and not solely on age. Close attention to long-term side effects with optimal supportive care should be considered. A survivorship care plan involving a multidisciplinary team is essential for young patients (Figure 2). Younger patients are also underrepresented in clinical trials and should be encouraged to participate for a better understanding of early-onset breast cancer.

\section{Acknowledgments}

This publication was made possible by Grant Number 1K12CA167540 through the National Cancer Institute (NCI) at the National Institutes for Health (NIH) and Grant Number UL1 TR000448 through the Clinical and Translational Science Award (CTSA) program of the National Cancer for Advancing Translational Sciences (NCATS) at the NIH. Its contents, however, are solely the responsibility of the authors and do not necessarily represent the official view of the NCI, NCATS, or NIH.

\section{Disclosure}

The authors report no conflicts of interest in this work.

\section{References}

1. Bleyer A, Barr R, Hayes-Lattin B, et al. The distinctive biology of cancer in adolescents and young adults. Nat Rev Cancer. 2008; 8(4):288-298.

2. Howlader N, Noone AM, Krapcho M, et al. SEER Cancer Statistics Review, 1975-2012. Bethesda, MD: National Cancer Institute; 2014. Based on November 2014 SEER data submission, posted to the SEER web site, April 2015. Available from: http://www.seer.cancer.gov/ csr/1975_2012/. Accessed November 12, 2015.

3. Smith RA, Saslow D, Sawyer KA, et al. American Cancer Society guidelines for breast cancer screening: update 2003. CA Cancer J Clin. 2003;53(3):141-169.

4. Fancher TT, Palesty JA, Paszkowiak JJ, Kiran RP, Malkan AD, Dudrick SJ. Can breast self-examination continue to be touted justifiably as an optional practice? Int J Surg Oncol. 2011;2011: 965464

5. Wilke LG, Broadwater G, Rabiner S, et al. Breast self-examination: defining a cohort still in need. Am J Surg. 2009;198(4):575-579.

6. An YY, Kim SH, Kang BJ, Park CS, Jung NY, Kim JY. Breast cancer in very young women ( $<30$ years): correlation of imaging features with clinicopathological features and immunohistochemical subtypes. Eur $J$ Radiol. 2015;84(10):1894-1902.

7. Goksu SS, Tastekin D, Arslan D, et al. Clinicopathologic features and molecular subtypes of breast cancer in young women (age $\leq 35$ ). Asian Pac J Cancer Prev. 2014;15(16):6665-6668.

8. Checka CM, Chun JE, Schnabel FR, Lee J, Toth H. The relationship of mammographic density and age: implications for breast cancer screening. AJR Am J Roentgenol. 2012;198(3):W292-W295.
9. Gilbert FJ, Tucker L, Gillan MG, et al. The TOMMY trial: a comparison of TOMosynthesis with digital MammographY in the UK NHS Breast Screening Programme - a multicentre retrospective reading study comparing the diagnostic performance of digital breast tomosynthesis and digital mammography with digital mammography alone. Health Technol Assess. 2015;19(4): i-Xxv, 1-136.

10. Zabicki K, Colbert JA, Dominguez FJ, et al. Breast cancer diagnosis in women $\leq 40$ versus 50 to 60 years: increasing size and stage disparity compared with older women over time. Ann Surg Oncol. 2006;13(8):1072-1077.

11. Partridge AH, Hughes ME, Ottesen RA, et al. The effect of age on delay in diagnosis and stage of breast cancer. Oncologist. 2012; 17(6):775-782.

12. Partridge AH, Gelber S, Piccart-Gebhart MJ, et al. Effect of age on breast cancer outcomes in women with human epidermal growth factor receptor 2-positive breast cancer: results from a herceptin adjuvant trial. J Clin Oncol. 2013;31(21):2692-2698.

13. Newell MS, D'Orsi C, Mahoney MC, et al. American College of Radiology ACR Appropriateness Criteria ${ }^{\circledR}$ Nonpalpable Mammographic Findings (Excluding Calcifications) [cited August 17, 2015]. Available from: http://www.acr.org/ /media/ACR/Documents/AppCriteria/ Diagnostic/NonpalpableMammographicFindings.pdf. Accessed November 12, 2015.

14. Harvey JA, Mahoney MC, Newell MS, et al. American College of Radiology ACR Appropriateness Criteria ${ }^{\circledR}$ Palpable Breast Masses [cited August 17, 2015]. Available from: http://www.acr.org/ /media/ ACR/Documents/AppCriteria/Diagnostic/PalpableBreastMasses.pdf. Accessed November 12, 2015.

15. Comstock CH, D'Orsi C, Bassett LW, et al. American College of Radiology ACR Appropriateness Criteria ${ }^{\circledR}$ Breast Microcalcifications Initial Diagnostic Workup [cited August 17, 2015]. Available from: http://www.acr.org/ /media/ACR/Documents/AppCriteria/Diagnostic/ BreastMicrocalcifications.pdf. Accessed November 12, 2015.

16. Dershaw DD, D’Orsi C, Mahoney MC, et al. ACR Practice Parameter for the Imaging Management of DCIS and Invasive Breast Carcinoma [cited August 17, 2015]. Available from: http://www.acr.org/ /media/ ACR/Documents/PGTS/guidelines/DCIS_Invasive_Breast_Carcinoma. pdf. Accessed November 12, 2015.

17. Collaborative Group on Hormonal Factors in Breast Cancer. Familial breast cancer: collaborative reanalysis of individual data from 52 epidemiological studies including 58,209 women with breast cancer and 101,986 women without the disease. Lancet. 2001; 358(9291):1389-1399.

18. Dite GS, Jenkins MA, Southey MC, et al. Familial risks, early-onset breast cancer, and BRCA1 and BRCA2 germline mutations. $J$ Natl Cancer Inst. 2003;95(6):448-457.

19. Lichtenstein P, Holm NV, Verkasalo PK, et al. Environmental and heritable factors in the causation of cancer - analyses of cohorts of twins from Sweden, Denmark, and Finland. N Engl J Med. 2000; 343(2):78-85

20. Peto J, Mack TM. High constant incidence in twins and other relatives of women with breast cancer. Nat Genet. 2000;26(4):411-414.

21. Michailidou K, Holm NV, Verkasalo PK, et al. Genome-wide association analysis of more than 120,000 individuals identifies 15 new susceptibility loci for breast cancer. Nat Genet. 2015;47(4): 373-380.

22. Michailidou K, Hall P, Gonzalez-Neira A, et al. Large-scale genotyping identifies 41 new loci associated with breast cancer risk. Nat Genet. 2013;45(4):353-361, 361. e1-e2.

23. Lalloo F, Varley J, Moran A, et al. BRCA1, BRCA2 and TP53 mutations in very early-onset breast cancer with associated risks to relatives. Eur J Cancer. 2006;42(8):1143-1150.

24. Haffty BG, Choi DH, Goyal S, et al. Breast cancer in young women (YBC): prevalence of BRCA1/2 mutations and risk of secondary malignancies across diverse racial groups. Ann Oncol. 2009;20(10):1653-1659. 
25. Peto J, Collins N, Barfoot R, et al. Prevalence of BRCA1 and BRCA2 gene mutations in patients with early-onset breast cancer. J Natl Cancer Inst. 1999;91(11):943-949.

26. Couch FJ, Hart SN, Sharma P, et al. Inherited mutations in 17 breast cancer susceptibility genes among a large triple-negative breast cancer cohort unselected for family history of breast cancer. J Clin Oncol. 2015;33(4):304-311.

27. Maxwell KN, Wubbenhorst B, D'Andrea K, et al. Prevalence of mutations in a panel of breast cancer susceptibility genes in BRCA1/2negative patients with early-onset breast cancer. Genet Med. 2015; 17(8):630-638.

28. Easton DF, Pharoah PD, Antoniou AC, et al. Gene-panel sequencing and the prediction of breast-cancer risk. $N$ Engl J Med. 2015; 372(23):2243-2257.

29. Copson E, Eccles B, Maishman T, et al. Prospective observational study of breast cancer treatment outcomes for UK women aged 18-40 years at diagnosis: the POSH study. J Natl Cancer Inst. 2013; 105(13):978-988.

30. Keegan TH, DeRouen MC, Press DJ, Kurian AW, Clarke CA. Occurrence of breast cancer subtypes in adolescent and young adult women. Breast Cancer Res. 2012;14(2):R55.

31. Ahn SH, Son BH, Kim SW, et al. Poor outcome of hormone receptorpositive breast cancer at very young age is due to tamoxifen resistance: nationwide survival data in Korea - a report from the Korean Breast Cancer Society. J Clin Oncol. 2007;25(17):2360-2368.

32. Walker RA, Lees E, Webb MB, Dearing SJ. Breast carcinomas occurring in young women (<35 years) are different. Br J Cancer. 1996;74(11):1796-1800

33. Gonzalez-Angulo AM, Broglio K, Kau SW, et al. Women age $\leq 35$ years with primary breast carcinoma: disease features at presentation. Cancer. 2005;103(12):2466-2472.

34. Xiong Q, Valero V, Kau V, et al. Female patients with breast carcinoma age 30 years and younger have a poor prognosis: the MD Anderson Cancer Center experience. Cancer. 2001;92(10):2523-2528.

35. Sidoni A, Cavaliere A, Bellezza G, Scheibel M, Bucciarelli E. Breast cancer in young women: clinicopathological features and biological specificity. Breast. 2003;12(4):247-250.

36. Collins LC, Marotti JD, Gelber S, et al. Pathologic features and molecular phenotype by patient age in a large cohort of young women with breast cancer. Breast Cancer Res Treat. 2012;131(3):1061-1066.

37. Gnerlich JL, Deshpande AD, Jeffe DB, Sweet A, White N, Margenthaler JA. Elevated breast cancer mortality in women younger than age 40 years compared with older women is attributed to poorer survival in early-stage disease. J Am Coll Surg. 2009;208(3): 341-347.

38. Lehmann BD, Bauer JA, Chen X, et al. Identification of human triplenegative breast cancer subtypes and preclinical models for selection of targeted therapies. J Clin Invest. 2011;121(7):2750-2767.

39. Millis SZ, Gatalica Z, Winkler J, et al. Predictive biomarker profiling of $>6000$ breast cancer patients shows heterogeneity in TNBC, with treatment implications. Clin Breast Cancer. Epub 2015 Apr 28.

40. Traina TA, Miller K, Yardley DA, et al. Results from a phase 2 study of enzalutamide (ENZA), an androgen receptor (AR) inhibitor, in advanced $\mathrm{AR}+$ triple-negative breast cancer (TNBC). Paper presented at: American Society of Clinical Oncology Annual Meeting, May 29, 2015, Chicago, IL.

41. Loi S, Sirtaine N, Piette F, et al. Prognostic and predictive value of tumor-infiltrating lymphocytes in a phase III randomized adjuvant breast cancer trial in node-positive breast cancer comparing the addition of docetaxel to doxorubicin with doxorubicin-based chemotherapy: BIG 02-98. J Clin Oncol. 2013;31(7):860-867.

42. Denkert C, von Minckwitz G, Brase JC, et al. Tumor-infiltrating lymphocytes and response to neoadjuvant chemotherapy with or without carboplatin in human epidermal growth factor receptor 2-positive and triple-negative primary breast cancers. J Clin Oncol. 2015;33(9):983-991.
43. Nanda R, Plimack ER, Dees EC, et al. A phase Ib multicohort study of MK-3475 in patients with advanced solid tumors. Paper presented at: American Society of Clinical Oncology, May 30, 2014, Chicago, IL.

44. Emens LA, Braiteh FS, Cassier P, et al. Inhibition of PD-L1 by MPDL3280A leads to clinical activity in patients with metastatic triple-negative breast cancer (TNBC). Paper presented at: American Association for Cancer Research, April 18-22, 2015, Pennsylvania, PA.

45. Azim HA Jr, Michiels S, Bedard PL, et al. Elucidating prognosis and biology of breast cancer arising in young women using gene expression profiling. Clin Cancer Res. 2012;18(5):1341-1351.

46. Anders CK, Hsu DS, Broadwater G, et al. Young age at diagnosis correlates with worse prognosis and defines a subset of breast cancers with shared patterns of gene expression. J Clin Oncol. 2008;26(20):3324-3330.

47. Ademuyiwa FO, Gao F, Hao L, et al. US breast cancer mortality trends in young women according to race. Cancer. 2015;121(9): 1469-1476.

48. Carey LA, Perou CM, Livasy CA, et al. Race, breast cancer subtypes, and survival in the Carolina Breast Cancer Study. JAMA. 2006;295(21):2492-2502.

49. Bauer KR, Brown M, Cress RD, Parise CA, Caggiano V. Descriptive analysis of estrogen receptor (ER)-negative, progesterone receptor (PR)-negative, and HER2-negative invasive breast cancer, the so-called triple-negative phenotype: a population-based study from the California cancer Registry. Cancer. 2007;109(9):1721-1728.

50. Lund MJ, Trivers KF, Porter PL, et al. Race and triple negative threats to breast cancer survival: a population-based study in Atlanta, GA. Breast Cancer Res Treat. 2009;113(2):357-370.

51. Johnson RH, Chien FL, Bleyer A. Incidence of breast cancer with distant involvement among women in the United States, 1976 to 2009. JAMA. 2013;309(8):800-805.

52. Anders CK, Johnson R, Litton J, Phillips M, Bleyer A. Breast cancer before age 40 years. Semin Oncol. 2009;36(3):237-249.

53. Fredholm H, Eaker S, Frisell J, Holmberg L, Fredriksson I, Lindman H. Breast cancer in young women: poor survival despite intensive treatment. PLoS One. 2009;4(11):e7695.

54. Nixon AJ, Neuberg D, Hayes DF, et al. Relationship of patient age to pathologic features of the tumor and prognosis for patients with stage I or II breast cancer. J Clin Oncol. 1994;12(5):888-894.

55. Fowble BL, Schultz DJ, Overmoyer B, et al. The influence of young age on outcome in early stage breast cancer. Int J Radiat Oncol Biol Phys. 1994;30(1):23-33.

56. Han W, Kim SW, Park IA, et al. Young age: an independent risk factor for disease-free survival in women with operable breast cancer. $B M C$ Cancer. 2004;4:82.

57. Han W, Kang SY; Korean Breast Cancer Soceity. Relationship between age at diagnosis and outcome of premenopausal breast cancer: age less than 35 years is a reasonable cut-off for defining young age-onset breast cancer. Breast Cancer Res Treat. 2010;119(1):193-200.

58. Sheridan W, Scott T, Caroline S, et al. Breast cancer in young women: have the prognostic implications of breast cancer subtypes changed over time? Breast Cancer Res Treat. 2014;147(3):617-629.

59. Mahmood U, Morris C, Neuner G, et al. Similar survival with breast conservation therapy or mastectomy in the management of young women with early-stage breast cancer. Int J Radiat Oncol Biol Phys. 2012;83(5):1387-1393.

60. Kroman N, Holtveg H, Wohlfahrt J, et al. Effect of breast-conserving therapy versus radical mastectomy on prognosis for young women with breast carcinoma. Cancer. 2004;100(4):688-693.

61. Kurian AW, Lichtensztajn DY, Keegan TH, Nelson DO, Clarke CA, Gomez SL. Use of and mortality after bilateral mastectomy compared with other surgical treatments for breast cancer in California, 1998-2011. JAMA. 2014;312(9):902-914.

62. Portschy PR, Kuntz KM, Tuttle TM. Survival outcomes after contralateral prophylactic mastectomy: a decision analysis. J Natl Cancer Inst. 2014;106(8):duj160. 
63. Mahmood U, Hanlon AL, Koshy M, et al. Increasing national mastectomy rates for the treatment of early stage breast cancer. Ann Surg Oncol. 2013;20(5):1436-1443.

64. Didier F, Radice D, Gandini S, et al. Does nipple preservation in mastectomy improve satisfaction with cosmetic results, psychological adjustment, body image and sexuality? Breast Cancer Res Treat. 2009;118(3):623-633.

65. Metcalfe KA, Cil TD, Semple JL, et al. Long-term psychosocial functioning in women with bilateral prophylactic mastectomy: does preservation of the nipple-areolar complex make a difference? Ann Surg Oncol. 2015;22(10):3324-3330.

66. Fisher B, Anderson S, Bryant J, et al. Twenty-year follow-up of a randomized trial comparing total mastectomy, lumpectomy, and lumpectomy plus irradiation for the treatment of invasive breast cancer. N Engl J Med. 2002;347(16):1233-1241.

67. Early Breast Cancer Trialists' Collaborative Group; Darby S, McGale P, Correa $\mathrm{C}$, et al. Effect of radiotherapy after breast-conserving surgery on 10-year recurrence and 15-year breast cancer death: meta-analysis of individual patient data for 10,801 women in 17 randomised trials. Lancet. 2011;378(9804):1707-1716.

68. NSABP Foundation Inc. Radiation therapy (WBI versus PBI) in treating women who have undergone surgery for ductal carcinoma in situ or stage I or stage II breast cancer [cited August 30, 2015]. Available from: https:/clinicaltrials.gov/ct2/show/NCT00103181. NLM identifier: NCT00103181. Accessed November 12, 2015.

69. Shah C, Vicini F, Wazer DE, Arthur D, Patel RR, et al. The American Brachytherapy Society consensus statement for accelerated partial breast irradiation. Brachytherapy. 2013;12(4):267-277.

70. The American Society of Breast Surgeons consensus statement for accelerated partial breast irradiation [cited August 30, 2015]. Available from: https://www.breastsurgeons.org/statements/PDF_Statements/ APBI.pdf. Accessed November 12, 2015.

71. Smith BD, Arthur DW, Buchholz TA, et al. Accelerated partial breast irradiation consensus statement from the American Society for Radiation Oncology (ASTRO). Int J Radiat Oncol Biol Phys. 2009; 74(4):987-1001.

72. Bartelink H, Maingon P, Poortmans $P$, et al. Whole-breast irradiation with or without a boost for patients treated with breast-conserving surgery for early breast cancer: 20-year follow-up of a randomised phase 3 trial. Lancet Oncol. 2015;16(1):47-56.

73. Smith BD, Bentzen SM, Correa CR, et al. Fractionation for whole breast irradiation: an American Society for Radiation Oncology (ASTRO) evidence-based guideline. Int J Radiat Oncol Biol Phys. 2011;81(1):59-68.

74. Overgaard M, Jensen MB, Overgaard J, et al. Postoperative radiotherapy in high-risk postmenopausal breast-cancer patients given adjuvant tamoxifen: Danish Breast Cancer Cooperative Group DBCG 82c randomised trial. Lancet. 1999;353(9165):1641-1648.

75. Overgaard M, Hansen PS, Overgaard J, et al. Postoperative radiotherapy in high-risk premenopausal women with breast cancer who receive adjuvant chemotherapy. Danish Breast Cancer Cooperative Group 82b Trial. N Engl J Med. 1997;337(14):949-955.

76. Ragaz J, livotto IA, Spinelli JJ, et al. Locoregional radiation therapy in patients with high-risk breast cancer receiving adjuvant chemotherapy: 20-year results of the British Columbia randomized trial. J Natl Cancer Inst. 2005;97(2):116-126.

77. Garg AK, Oh JL, Oswald MJ, et al. Effect of postmastectomy radiotherapy in patients $<35$ years old with stage II-III breast cancer treated with doxorubicin-based neoadjuvant chemotherapy and mastectomy. Int J Radiat Oncol Biol Phys. 2007;69(5):1478-1483.

78. Wallgren A, Bonetti M, Gelber RD, et al. Risk factors for locoregional recurrence among breast cancer patients: results from International Breast Cancer Study Group Trials I through VII. J Clin Oncol. 2003;21(7):1205-1213.

79. Jagsi R, Raad RA, Goldberg S, et al. Locoregional recurrence rates and prognostic factors for failure in node-negative patients treated with mastectomy: implications for postmastectomy radiation. Int J Radiat Oncol Biol Phys. 2005;62(4):1035-1039.
80. Yildirim E, Berberoglu U. Can a subgroup of node-negative breast carcinoma patients with T1-2 tumor who may benefit from postmastectomy radiotherapy be identified? Int J Radiat Oncol Biol Phys. 2007; 68(4):1024-1029.

81. Early Breast Cancer Trialists' Collaborative Group. Effects of chemotherapy and hormonal therapy for early breast cancer on recurrence and 15-year survival: an overview of the randomised trials. Lancet. 2005; 365(9472):1687-1717.

82. Davies C, Pan H, Godwin J, et al. Long-term effects of continuing adjuvant tamoxifen to 10 years versus stopping at 5 years after diagnosis of oestrogen receptor-positive breast cancer: ATLAS, a randomised trial. Lancet. 2013;381(9869):805-816.

83. Gray RG, Rea D, Handley K, et al. aTTom: Long-term effects of continuing adjuvant tamoxifen to 10 years versus stopping at 5 years in 6,953 women with early breast cancer. J Clin Oncol. 2013;31:suppl;abstr 5.

84. Pagani O, O’Neill A, Castiglione M, et al. Prognostic impact of amenorrhoea after adjuvant chemotherapy in premenopausal breast cancer patients with axillary node involvement: results of the International Breast Cancer Study Group (IBCSG) Trial VI. Eur J Cancer. 1998; 34(5):632-640.

85. International Breast Cancer Study Group; Colleoni M, Gelber S, Goldhirsch A, et al. Tamoxifen after adjuvant chemotherapy for premenopausal women with lymph node-positive breast cancer: International Breast Cancer Study Group Trial 13-93. J Clin Oncol. 2006; 24(9):1332-1341.

86. Swain SM, Jeong JH, Wolmark N. Amenorrhea from breast cancer therapy - not a matter of dose. N Engl J Med. 2010;363(23):2268-2270.

87. Francis PA, Regan MM, Fleming GF, et al. Adjuvant ovarian suppression in premenopausal breast cancer. $N$ Engl J Med. 2015;372(5): 436- 446.

88. Pagani O, Regan MM, Walley BA, et al. Adjuvant exemestane with ovarian suppression in premenopausal breast cancer. $N$ Engl J Med. 2014;371(2):107-118.

89. Bernhard J, Luo W, Ribi K, et al. Patient-reported outcomes with adjuvant exemestane versus tamoxifen in premenopausal women with early breast cancer undergoing ovarian suppression (TEXT and SOFT): a combined analysis of two phase 3 randomised trials. Lancet Oncol. 2015;16(7):848-858.

90. Piccart-Gebhart MJ, Procter M, Leyland-Jones B, et al. Trastuzumab after adjuvant chemotherapy in HER2-positive breast cancer. $N$ Engl J Med. 2005;353(16):1659-1672.

91. Perez EA, Suman VJ, Davidson NE, et al. Sequential versus concurrent trastuzumab in adjuvant chemotherapy for breast cancer. J Clin Oncol. 2011;29(34):4491-4497.

92. Romond EH, Perez EA, Bryant J, et al. Trastuzumab plus adjuvant chemotherapy for operable HER2-positive breast cancer. $N$ Engl J Med. 2005;353(16):1673-1684

93. Slamon D, Eiermann W, Robert N, et al. Adjuvant trastuzumab in HER2positive breast cancer. $N$ Engl J Med. 2011;365(14):1273-1283.

94. Baselga J, Cortés J, Kim SB, et al. Pertuzumab plus trastuzumab plus docetaxel for metastatic breast cancer. $N$ Engl J Med. 2012; 366(2):109-119.

95. Schneeweiss A, Chia S, Hickish T, et al. Pertuzumab plus trastuzumab in combination with standard neoadjuvant anthracycline-containing and anthracycline-free chemotherapy regimens in patients with HER2positive early breast cancer: a randomized phase II cardiac safety study (TRYPHAENA). Ann Oncol. 2013;24(9):2278-2284.

96. Gianni L, Pienkowski T, Im YH, et al. Efficacy and safety of neoadjuvant pertuzumab and trastuzumab in women with locally advanced, inflammatory, or early HER2-positive breast cancer (NeoSphere): a randomised multicentre, open-label, phase 2 trial. Lancet Oncol. 2012; 13(1):25-32.

97. Christinat A, Pagani O. Fertility after breast cancer. Maturitas. 2012;73(3):191-196.

98. Rodriguez-Wallberg KA, Oktay K. Options on fertility preservation in female cancer patients. Cancer Treat Rev. 2012;38(5):354-361. 
99. Ronn R, Holzer HE. Oncofertility in Canada: the impact of cancer on fertility. Curr Oncol. 2013;20(4):e338-e344.

100. Walshe JM, Denduluri N, Swain SM. Amenorrhea in premenopausal women after adjuvant chemotherapy for breast cancer. J Clin Oncol. 2006;24(36):5769-5779.

101. Donnez J, Dolmans MM. Fertility preservation in women. Nat Rev Endocrinol. 2013;9(12):735-749.

102. Loren AW, Mangu PB, Beck LN, et al. Fertility preservation for patients with cancer: American Society of Clinical Oncology clinical practice guideline update. J Clin Oncol. 2013;31(19):2500-2510.

103. Friedler S, Koc O, Gidoni Y, Raziel A, Ron-El R. Ovarian response to stimulation for fertility preservation in women with malignant disease: a systematic review and meta-analysis. Fertil Steril. 2012; 97(1):125-133

104. Moore HC, Unger JM, Phillips KA, et al. Goserelin for ovarian protection during breast-cancer adjuvant chemotherapy. $N$ Engl $J$ Med. 2015;372(10):923-932

105. Azim HA Jr, Santoro L, Pavlidis N, et al. Safety of pregnancy following breast cancer diagnosis: a meta-analysis of 14 studies. Eur $J$ Cancer. 2011;47(1):74-83.

106. Azim HA Jr, Kroman N, Paesmans M, et al. Prognostic impact of pregnancy after breast cancer according to estrogen receptor status: a multicenter retrospective study. J Clin Oncol. 2013;31(1): 73-79.

107. Kroman N, Jensen MB, Wohlfahrt J, Ejlertsen B; Danish Breast Cancer Cooperative Group. Pregnancy after treatment of breast cancer - a population-based study on behalf of Danish Breast Cancer Cooperative Group. Acta Oncol. 2008;47(4):545-549.

108. Valachis A, Tsali L, Pesce LL, et al. Safety of pregnancy after primary breast carcinoma in young women: a meta-analysis to overcome bias of healthy mother effect studies. Obstet Gynecol Surv. 2010; 65(12):786-793.

109. International Breast Cancer Study Group. Pregnancy Outcome and Safety of Interrupting Therapy for Women With Endocrine Responsive Breast Cancer (POSITIVE) [cited August 17, 2015]. Available from: https://clinicaltrials.gov/ct2/show/NCT02308085?term $=02308085 \&$ ra nk=1. NLM identifier: NCT02308085. Accessed November 12, 2015.

110. Pagani O, Azim H Jr. Pregnancy after breast cancer: myths and facts. Breast Care (Basel). 2012;7(3):210-214.

111. Azim HA Jr, Metzger-Filho O, de Azambuja E, et al. Pregnancy occurring during or following adjuvant trastuzumab in patients enrolled in the HERA trial (BIG 01-01). Breast Cancer Res Treat. 2012;133(1): 387-391.

112. Saunders CM, Baum M. Breast cancer and pregnancy: a review. $J R$ Soc Med. 1993;86(3):162-165.

113. Anderson JM. Mammary cancers and pregnancy. Br Med J. 1979;1(6171):1124-1127.

114. Noyes RD, Spanos WJ Jr, Montague ED. Breast cancer in women aged 30 and under. Cancer. 1982;49(6):1302-1307.

115. Vashi R, Hooley R, Butler R, Geisel J, Philpotts L. Breast imaging of the pregnant and lactating patient: imaging modalities and pregnancy-associated breast cancer. AJR Am J Roentgenol. 2013; 200(2):321-328.

116. Heymann JJ, Halligan AM, Hoda SA, Facey KE, Hoda RS. Fine needle aspiration of breast masses in pregnant and lactating women: experience with 28 cases emphasizing Thinprep findings. Diagn Cytopathol. 2015;43(3):188-194.

117. ACOG Committee on Obstetric Practice. ACOG Committee Opinion. Number 299, September 2004 (replaces No 158, September 1995) Guidelines for diagnostic imaging during pregnancy. Obstet Gynecol. 2004;104(3):647-651.

118. Bural GG, Laymon CM, Mountz JM. Nuclear imaging of a pregnant patient: should we perform nuclear medicine procedures during pregnancy? Mol Imaging Radionucl Ther. 2012;21(1):1-5.

119. Toesca A, Gentilini O, Peccatori F, Azim HA Jr, Amant F. Locoregional treatment of breast cancer during pregnancy. Gynecol Surg. 2014;11(4):279-284.
120. Chen Z, King W, Pearcey R, Kerba M, Mackillop WJ. The relationship between waiting time for radiotherapy and clinical outcomes: a systematic review of the literature. Radiother Oncol. 2008;87(1): $3-16$.

121. Mazonakis M, Varveris H, Damilakis J, Theoharopoulos N, Gourtsoyiannis N. Radiation dose to conceptus resulting from tangential breast irradiation. Int J Radiat Oncol Biol Phys. 2003;55(2): 386-391.

122. Gentilini O, Cremonesi M, Toesca A, et al. Sentinel lymph node biopsy in pregnant patients with breast cancer. Eur J Nucl Med Mol Imaging. 2010;37(1):78-83.

123. Gropper AB, Calvillo KZ, Dominici L, et al. Sentinel lymph node biopsy in pregnant women with breast cancer. Ann Surg Oncol. 2014;21(8):2506-2511.

124. Ring AE, Smith IE, Jones A, Shannon C, Galani E, Ellis PA. Chemotherapy for breast cancer during pregnancy: an 18-year experience from five London teaching hospitals. J Clin Oncol. 2005; 23(18):4192-4197.

125. Hahn KM, Johnson PH, Gordon N, et al. Treatment of pregnant breast cancer patients and outcomes of children exposed to chemotherapy in utero. Cancer. 2006;107(6):1219-1226.

126. Berry DL, Theriault RL, Holmes FA, et al. Management of breast cancer during pregnancy using a standardized protocol. J Clin Oncol. 1999;17(3):855-861.

127. Murthy RK, Theriault RL, Barnett CM, et al. Outcomes of children exposed in utero to chemotherapy for breast cancer. Breast Cancer Res. 2014;16(6):500

128. Zagouri F, Sergentanis TN, Chrysikos D, Papadimitriou CA, Dimopoulos MA, Bartsch R. Trastuzumab administration during pregnancy: a systematic review and meta-analysis. Breast Cancer Res Treat. 2013;137(2):349-357.

129. Shapiro CL, Halabi S, Hars V, et al. Zoledronic acid preserves bone mineral density in premenopausal women who develop ovarian failure due to adjuvant chemotherapy: final results from CALGB trial 79809 Eur J Cancer. 2011;47(5):683-689.

130. Sverrisdottir A, Fornander T, Jacobsson H, von Schoultz E, Rutqvist LE. Bone mineral density among premenopausal women with early breast cancer in a randomized trial of adjuvant endocrine therapy. J Clin Oncol. 2004;22(18):3694-3699.

131. Gnant M, Mlineritsch B, Luschin-Ebengreuth G, et al. Adjuvant endocrine therapy plus zoledronic acid in premenopausal women with early-stage breast cancer: 5-year follow-up of the ABCSG-12 bone-mineral density substudy. Lancet Oncol. 2008;9(9):840-849.

132. Brufsky AM, Harker WG, Beck JT, et al. Final 5-year results of Z-FAST trial: adjuvant zoledronic acid maintains bone mass in postmenopausal breast cancer patients receiving letrozole. Cancer. 2012;118(5):1192-1201.

133. Smith MR, Egerdie B, Hernández Toriz N, et al. Denosumab in men receiving androgen-deprivation therapy for prostate cancer. $N$ Engl J Med. 2009;361(8):745-755.

134. Ellis GK, Bone HG, Chlebowski R, et al. Randomized trial of denosumab in patients receiving adjuvant aromatase inhibitors for nonmetastatic breast cancer. J Clin Oncol. 2008;26(30):4875-4882.

135. Gnant MF, Mlineritsch B, Luschin-Ebengreuth G, et al. Zoledronic acid prevents cancer treatment-induced bone loss in premenopausal women receiving adjuvant endocrine therapy for hormone-responsive breast cancer: a report from the Austrian Breast and Colorectal Cancer Study Group. J Clin Oncol. 2007;25(7):820-828.

136. Coleman R, Cameron D, Dodwell D, et al. Adjuvant zoledronic acid in patients with early breast cancer: final efficacy analysis of the AZURE (BIG 01/04) randomised open-label phase 3 trial. Lancet Oncol. 2014;15(9):997-1006.

137. Gnant M, Pfeiler G, Dubsky PC, et al. Adjuvant denosumab in breast cancer (ABCSG-18): a multicentre, randomised, double-blind, placebo-controlled trial. Lancet. 2015;386(9992):433-443.

138. American Cancer Society. Breast Cancer Facts and Figures 2015-2016. Atlanta, CA: American Cancer Society; 2015. 


\section{Publish your work in this journal}

Breast Cancer: Targets and Therapy is an international, peer- View the full aims and scopes of this journal here. The manuscript reviewed open access journal focusing on breast cancer research, identification of therapeutic targets and the optimal use of preventative and integrated treatment interventions to achieve improved outcomes, enhanced survival and quality of life for the cancer patient. management system is completely online and includes a very quick and fair peer-review system, which is all easy to use. Visit http:// www.dovepress.com/testimonials.php to read real quotes from published authors.

Submit your manuscript here: http://www.dovepress.com/breast-cancer---targets-and-therapy-journal 